\title{
Assessment of Diabetes Nutrition Knowledge and Impact of Nutrition Education Programs on Home Economics Teachers
}

\author{
R. Barake ${ }^{1}$, F. Ismail' ${ }^{1}$ D. Alkaed ${ }^{1}$.
}

1Dasman Diabetes Institute, Nutrition, Dasman, Kuwait.

\section{AIMS}

The aim of this program was to assess diabetes nutrition knowledge, and measure the impact of a nutrition education program developed to improve knowledge, skills and empower 25 home economics teachers from public schools in Kuwait.

\section{METHODOLOGY}

A program was developed to address theoretical and practical aspects of nutrition education for diabetes, obesity, anemia, celiac disease, vitamin $\mathrm{D}$ deficiency, healthy cooking, food label reading and bone health. Additionally, the training program was designed to develop skills in measuring waist to hip ratio, calculating body mass index (BMI) and classifying categories of obesity. Twenty-five home economics teachers attended this program, ages ranged from $30-50$ years. Participants were randomly selected from intermediate and secondary schools representing all 6 governorates of the State of Kuwait. A 3-day-per-week program over one month was delivered through different formats. Preassessment and post assessment data were collected where applicable, and evaluation of classes were conducted to address learners' needs and improve the program.

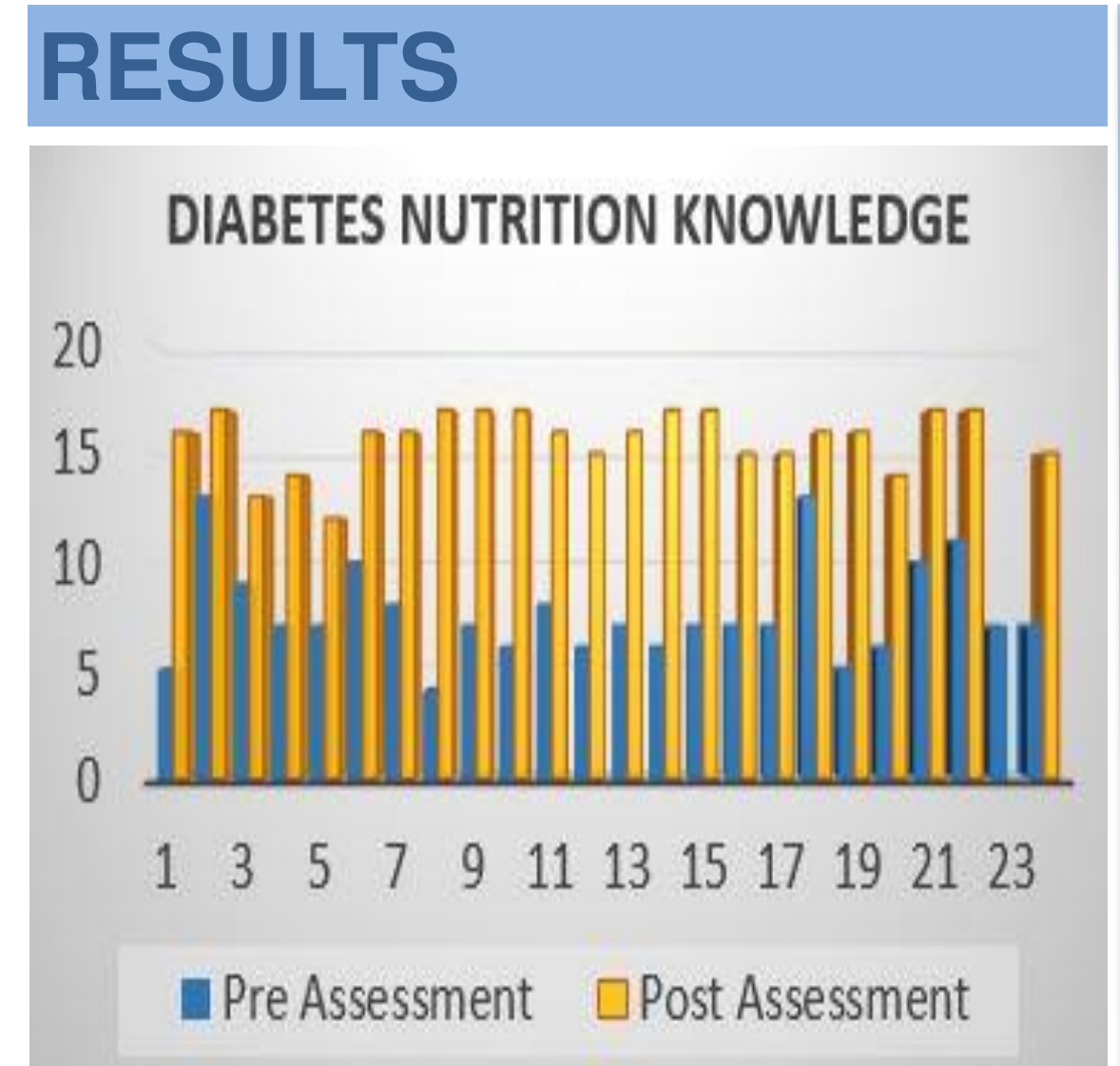

Diabetes nutrition knowledge improved significantly $(7.8 \pm 5.7,15.7 \pm 2.1$; $\mathrm{p}<0.001)$

\section{VITAMIN D KNOWLEDGE}

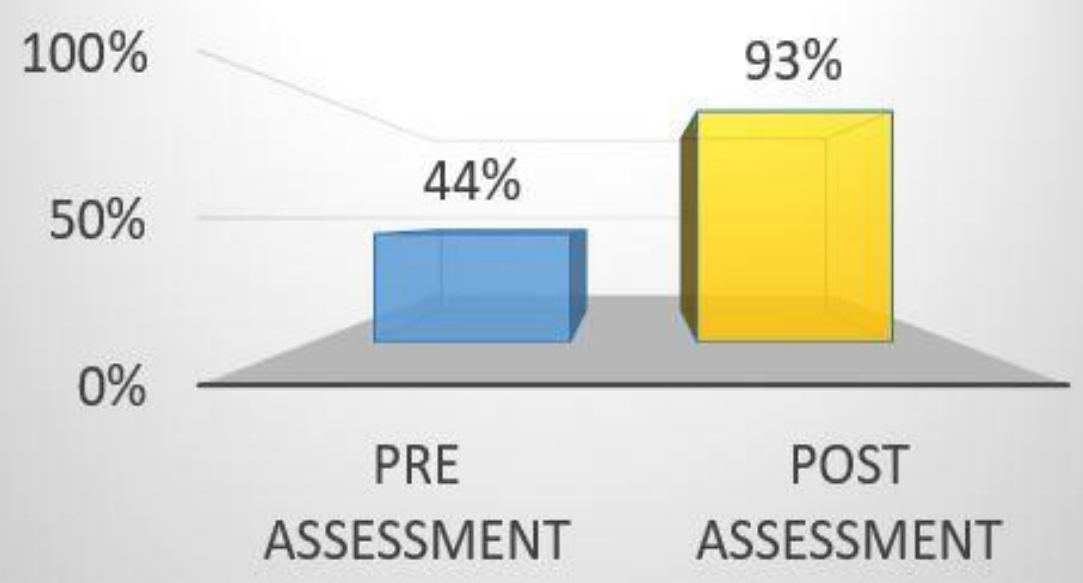

Vitamin D knowledge improved significantly $(6.6 \pm 3.8,13.9 \pm 1.2$; $\mathrm{p}<0.001)$

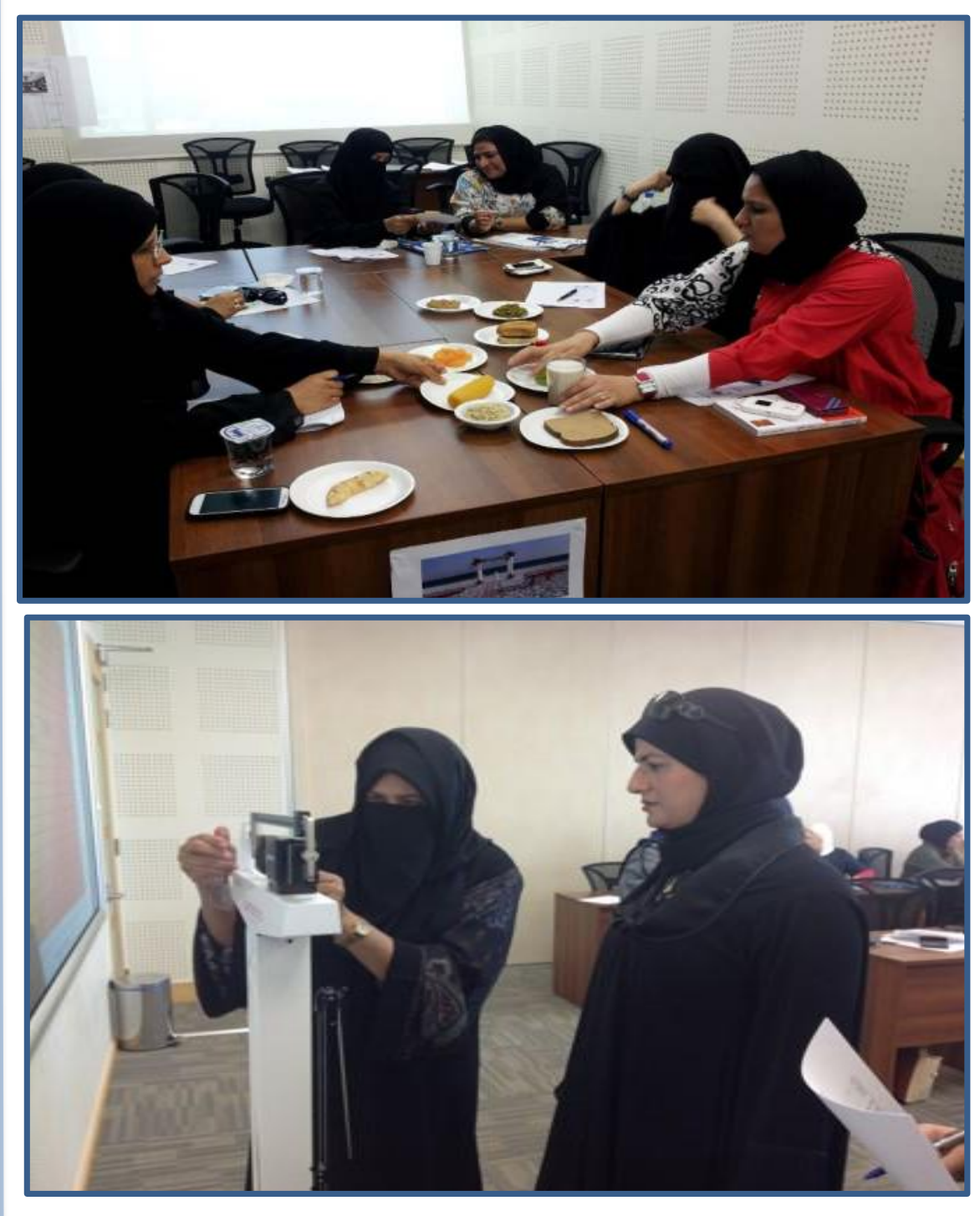

Interactive nutrition education sessions

\section{DISCUSSION}

Findings from this study indicate that diabetes nutrition knowledge and nutrition knowledge in general among home economics teachers is not optimal. Nutrition knowledge among teachers attending nutrition education programs has improved significantly. Teachers attending practical sessions and workshops developed skills in taking proper measurements of hip to waist ratio, calculating BMI and classifying obesity in the correct categories.

\section{CONCLUSION}

Empowering teachers and developing their knowledge may contribute to help their students cope with, and manage diabetes, obesity, and other health conditions better.

\section{ACKNOWLEDGMENT}

Nutrition team

Diabetes education team

Pharmacists team

Medical fitness team

Home economics teachers Ministry of Education

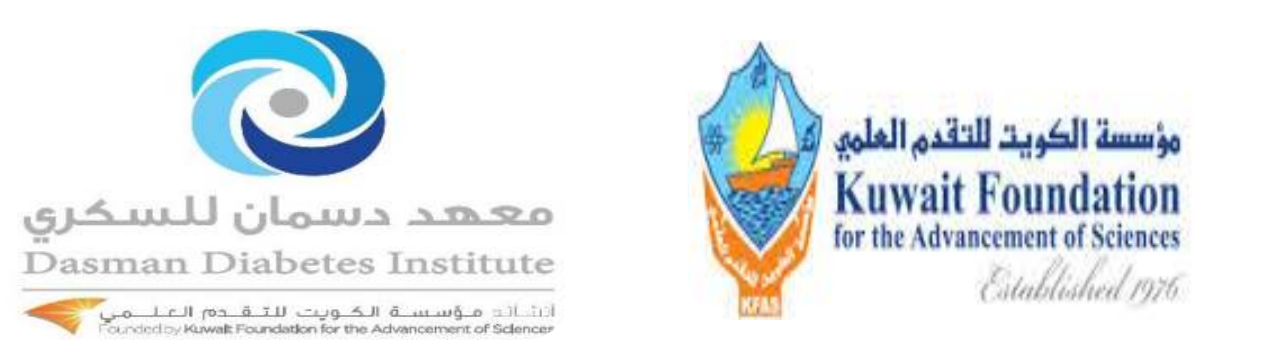

